\title{
Execution of e-books \& its impact in academic and research libraries of India: An evaluative study
}

\author{
Sivamay Bhattacharjya \\ Research Scholar, Dept. of Education, Ashutosh Mukhopadhyay School of Educational Sciences, \\ Assam University, Silchar-788011
}

\begin{abstract}
The paper describes the impact of the use of e-books in research and study in academic institutions. Electronic books and periodicals provide flexibility, economy, and efficiency which traditional publications cannot match. However, many times wrong messages like increasing costs, meagre platform functionalities, inadequate research tools etc. can negate these advantages, creating inter-departmental tension among the users, during planning or acquisition, in many academic premier research institutions and Universities. The paper addresses these issues and discusses such aspects as what is meant by "e-books", features and benefits of ebooks platform, how e-books can be managed \& procured in the library environment, what are the best practices for implementing an e-Book strategy to ensure that academic libraries enjoy the smoothest possible transition to e-Books and also its impact on the research output.
\end{abstract}

Keyword: e-books implementation, usage, Library best practices, e-books execution, research libraries

\section{INTRODUCTION:}

E-books are a hot topic. Traditional book publishing, especially in the academic world, is changing at a rapid pace. E-Books form a growing part of the collections at research and academic libraries. Although still in the early stages of adoption, eBooks have demonstrated advantages in the areas of accessibility, functionality, and cost-effectiveness. End users are just beginning to incorporate eBooks into their information experience and research habits. Libraries are eager to learn more about the rate of eBook adoption among their end users and the ways in which users are interacting with eBooks. The question on everybody's mind is what direction book publishing will take? Will print survive in the Google-generation, or is it destined to be totally replaced by eBooks? In the field of Science, Technology and Medicine (STM), there are a number of publishers in the market place viz. Cambridge University Press( CUP), Elsevier, McGraw-Hill Education ,Oxford University Press ( OUP), Palgrave Macmillan, Pearson, Springer, Sage Taylor \& Francis etc. Some of the publishers like OUP, Sage, CUP etc. are strong in Humanities and Social Science as well. As far as the e-books scenario is concerned - most of these publishers launched their e-books program in the year 2005-2006. Since that start there has been a large pickup. The electronic content amount is increasing, and the number of customers is growing rapidly across the globe in different areas. There had been a major initiatives right from the strategy implementation to the accessibility of e-books. The perception of researchers and end users regarding the platform that drives the usage and discoverability. The survey uncovered some encouraging results regarding eBook adoption. As electronic publishing matures, research and academic libraries are beginning to supplement their print holdings with electronic publications. This transition began with scientific journals, and is now advancing into academic and scholarly books, as well. In the past few years, corporate and government libraries have also begun acquiring eBooks along with print holdings. eBooks provide substantial advantages to libraries and their users. Both parties gain from 24/7 access, simultaneous user access, wider selection, and immediate updates, while libraries also benefit from back-end efficiencies, such as a lack of storage requirements, reduced maintenance costs, and reduced staffing time for physical handling and processing of print books. Different study and market research done by the content providers on user behavior revealed some uncovered facts on the use of e-books. It was also observed that more than 78\% STM content users were aware of e-Books and had accessed them at least once. Respondents also overwhelmingly said that eBooks are useful and that they would like to incorporate eBooks into their information experience more frequently. In present online environment, STM eBook publishers offer an unparalleled volume of content on an expansive range of topics. User behavior survey on STM content revealed that users mostly access eBooks for research and study purposes and the types of eBooks most frequently used are reference works and textbooks. Different market research surveys done by 
one of the leading STM Publishers within its own content consist of monographs, eBook series, Major Reference Works (MRW) and textbooks. explored that users most frequently locate e-Books through general search engines like Google as well as through online library catalogs. In addition to that, factors like convenience, accessibility, and enhanced functionality are regarded as the primary benefits of eBooks. Though print books are perceived to have an advantage in ease and enjoyability of reading, however, users expect that their transition to e-Books will enhance the research-related activities in faster way. Overall, the survey results indicate that e-Books are best suited for research purposes and for all reference works or in a search environment where the user needs to locate specific information. Moreover, it was observed that for research purposes, Users are not reading eBooks cover-to-cover in the traditional sense but instead approach them as a resource for finding answers to research questions. eBooks have the potential to stimulate new forms of book content usage and will require libraries to think differently about how to accommodate the needs of users as their eBook collections grow. Viewing eBooks through the lens of traditional print book usage might cause libraries to miss important opportunities for enhancing the user research experience in universities and R \& D institutions. The paper also highlights the ways in which electronic content and more specifically e-Books affect research and study in general and the future of research and study primarily through the use of electronic content, or e-books in particular.

\section{What are eBooks?}

In principle, an eBook is quite similar to a print book: only the medium is different. For a traditional print book the medium is paper. Because an e-Book is the digital representation of the printed material (print book), the medium can vary from a (laptop) computer, to digital e-Book reader, PDA, mobile phone or even (through a desktop printer) traditional paper. Usually the content is available in PDF or HTML format, but also plain text or XML formats., This makes the content much more versatile, and flexible than the traditional print book. Moreover, an e-Book can be fully indexed. Readers can also find e- books through search engines (such as Google), the library catalog (OPAC) or the publisher platform.

So the primary difference between print books and e-Books is that eBooks are exposed and visible to a larger audience. Print books can only be read by physically going to a library, while through the internet, basically the whole world has access to the e-content at any time of the day.

\section{Who uses eBooks?}

In the Academic and professional book market scenario a number of content user groups exist. The information user behavior depends on these groups to a large extent. The smallest group is basic and applied researchers, who mostly read but also write books. In addition, developers enlarge this group. Finally, a large user base of students complements the audience for academic (e)Books. Comparison of the audience groups for scientific journals and books shows that only the tip of the pyramid (Figure-1 below) is core users who both read and write content for journals. Thus, the audience for journals is much smaller than the audience for books. Clearly, the core user group for books is bigger by far than the core user group for academic journals. In a nutshell, we can say that "One needs to read books, before one can understand (scientific) journals. Journals are basically for specific Research in a particular area, whereas books cover a large part right from basic level to the research.CIBER (Centre for Information Behaviour and the Evaluation of Research) pointed out "eBooks will be the next publishing success story, although demand here could be even more spectacular, simply as a result of the enormous size of the student population, hungry for highly digested content."

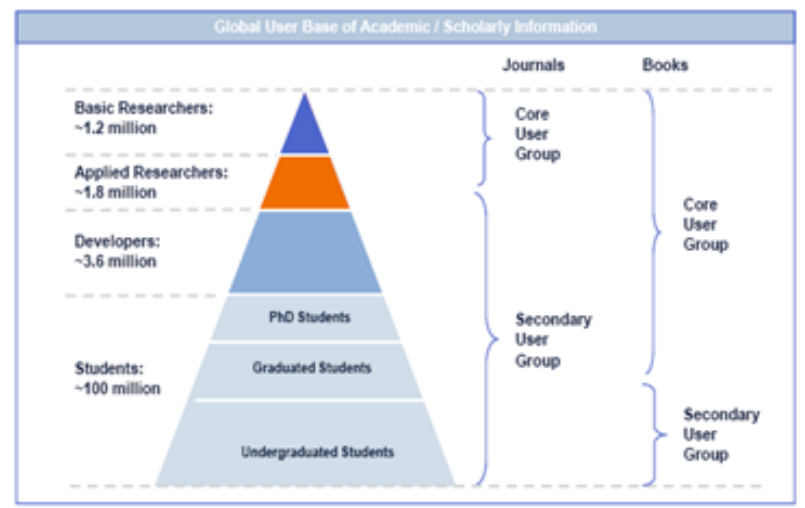

Figure 1 - Pyramid of user groups for academic information-Audience for e-Books larger than for journals 


\section{eBooks - Costs and Benefits to Academic and Research Libraries: Indian Scanario}

The consortia concept in India is of recent origin and has been discussed about it since 1990. It started with Consortium for Material Science and Aerospace Collection of the NAL in 1998 for a few databases. It could not sustain for various reasons. This was followed by TIFR Consortium(2000), which used the consortia model offered by Springer for multi-site licensing and cross sharing of content among all its branch libraries affiliated to TIFR. Perhaps this is the first known successful consortia in the country. Thereafter few leading libraries and publishers/vendors joined together and formed few open and non-informal consortia projects.Notable ones are Forum for Resource Sharing in Astronomy ( FORSA) 's Indian Astrophysics Consortium and IIM Libraries Consortium for e-journals. This was followed by CSIR e-journal consortium( Now NKRC of DST and CSIR Libraries. ) DAE Consortium for its affiliated institutes with single publisherElsevier. During 2000, INDEST conostium came up covering the premier Technical and management institutions alongwith the self supported Engineering colleges (INDEST-AICTE).Likewise many consortium emerged in India, viz. HELINET, UGC -InfoNET, CeRA of ICAR, DRDO, ISI Consortium, ErMED, MCIT , DBT etc.

The initiative to provide the e-content to the Universities and academic institutions came up in India through UGC -INFLIBNET, (a MHRD funded consortia initiative), more than decade ago, which is considered as one of the well planned, multi-sector consortium of the country. However, all these initiatives are primarily focused on Journals only. Till today, there is no significant e-books procurement initiative through such consortium.

Many academic libraries recognize that eBooks offer an ideal opportunity to increase existing collections while enhancing users' experiences at the same time. Some libraries have adopted significant e-Book acquisitions programs; however, in India, still the market for e-Books is just developing. Digital delivery enables publishers to create large, cost-effective packages. These packages allow libraries to significantly increase the number of titles they can purchase and extend them to remote branches. In many of the premier R \& $\mathrm{D}$ institutes of India and Government funded universities, the availability of e-books offers better wider range of content to users, with journals being the logical first step in developing electronic collections. Increasingly, journal collections at several libraries are approaching electronic-only status.

Recently, National Library and Information Services Infrastructure for Scholarly Content (N-LIST) consortium formed by the INFLIBNET focusing mainly for the undergraduate level research, subscribed ebooks from the different publishers and vendors.From Year 2014, N-LIST Programme is incorporated under UGC-INFONET Digital Library Consortium as college Component. The colleges (except Agriculture, Engineering, Management, Medical, Pharmacy, Dentistry and Nursing) in India are eligible to get access eresources under NLIST Programme. Through this project, as of now, around 5,500 degree colleges in India got the advantages of using e-books for their study as well UG research.

Some of the premier research institute in India subscribed e-books on individual level from their own libraryfunds and it was found that the usage of e-books very high in these institutions. This reflects the utilization, demand and acceptance of e-booksIn 2008, a leading STM Publishers Springer(erstwhile Springer Science and Business Media) published a white paper "e-Books - The End User Perspective" based on a survey conducted on a number of end-users at some selected universities and institutions across the world about the perception of e-books. The Librarian of Indian Institute of Science(IISc), Bangalore said,

"A large number of eBooks can be carried in a laptop, where transferring the print books is a real pain. Also if the computer screen is suitable, it doesn't give much difference with the print book. Of course, print books have different glamour, it's not quite right to compare them."

\section{Strategy \& Executions of e-books in academic and Research Libraries:}

In Indian Libraries, e-books procurement is in embryonic stage, however after years of expansion efforts with high opportunities, e-books have instigated to strengthen their place as a central part of the information experience. Almost all the premier Research and academic libraries particularly in $R$ \& $D$ Institutions and Universities are increasingly building their e-Book collections into a valuable resource for their users. However, in an institutional library, collection development strategy played a major role for implementation and enhancing the research. Some other propositions include selection of publishers and 
resources, evaluation of publishers' business model, digital rights management policies, Archival access policies etc. Besides communication to users is also a major aspect in e-books executions.

In traditionalLibraries, it is a common practice to procure e-Books through "pick and choose" basis, through which libraries acquire individual titles and this basically helps institutions with the elasticity to supplement their print catalogs with targeted selections and thus implementing e-Books strategy very slowly. On the other hand , "critical mass strategy" consists of focus on initial procurements to build a huge mass of subject-specific content large enough which encourage the users on intense usage of the content.

Since Library budget is a major concern in developing countries, "pick and Choose" model gains more acceptance among the librarian and resource purchase decision makers in many medium size libraries across India, because pick and choose strategies require less initial investment of time and budget. However, over the long term, greater overall costs with more limiting Digital Rights Management (DRM) policies can make pick and choose an unattractive proposition. While critical mass strategies do not provide the specificity of pick and choose, they are more cost effective, tend to have less restrictive DRM policies attached to content, and provide more overall content usage for a given budget. By buying eBooks in collections, purchasers achieve a lower cost-per-title when cost-per-e-title is compared to cost-per-print-title. With added functionalities and features such as easy searchability and virtual unlimited availability, eBook-usage offers a dramatically increased "title reach" (number of books that are used) compared to the print usage.

Generally, for researchers, the resources like reference materials, monographs etc. particularly in the Science, Technology and Medicine (STM) fields, are most preferred resources in an e-books collection. So, STM users tend to be more familiar with online research than those of other disciplines, and so their research styles expose the advantages of eBooks very quickly. After establishing sufficient area-specific coverage, libraries should seek a test group of early adopters willing to experiment with all available research features. In this way, library will have a realistic assessment and accordingly can broaden their collections based on the researchers need. Another important aspect in e-books execution is the assessment of publishers' business model. Every publisher offers different tools and policies to provide access to the institutions. Thus it creates confusion among the institutional purchase decision makers to justify the execution of the resources specially in case of e-books purchase. To sort out these challenges, the librarian should take pro-active interaction with the publishers to assess the following features :

\section{- Digital Rights Management (DRM)}

DRM policies shield publishers' rights by limiting the end user's ability to use many features like copy, forward, download etc. . These fortifications may prevent users' research approaches, contradicting many of the values of electronic documents (such as cut and paste), or the ability to have multiple users access content simultaneously.

\section{- Concurrent users}

The knowledge manager of the institutions should search for those content publishers which does not have any limitations on concurrent access, as many electronic titles will have very high demand for many users in the same institutions.

\section{- COUNTER compliance}

The COUNTER initiative is the de facto standard for usage measurement in the reference industry. Publishers that do not provider COUNTER-compliant tools will be difficult to benchmark, making cost justifications difficult and time-consuming or impossible.

\section{- Availability of MARC records}

The Librarian should observe that the whether the content providers or publishers have appropriate MARC records available in an easily-imported format to integrate electronic collections into the library OPAC systems. e-book publishers should provide ways through which users can find e-book content. That information can be in the form of MARC Records, or URL lists that can be inserted in the OPAC, Link resolvers, as well as A-Z lists.

\section{Ownership vs. subscription}

It is beyond the scope of subscription model technology to keep the purchased content and so sometimes the content purchased under subscription model leave most critical assets vulnerable to contract disputes. So, the library should opt out those publishers who provide complete ownership of the content. 
However, the perception varies in case to case. Subscription model also has its own benefits. Mostly in case of the content like computer Science, Technology, professional text books which changes with time, the library should go for subscription model to justify the purchases. The decision makers in the institutions should look for publishers who provide flexible package arrangements to meet users' needs. As an instance, e-books packages based on subject collection with R \& D oriented approach allow the institutions to supplement collections costeffectively only by paying for the most needed content.

\section{- Archiving policies}

Libraries should retain day-to-day and long-term access to e-Book content, irrespective of publisher's status. Publishers should commit and provide perpetual content access to libraries in business agreements and participate in an archiving program such as LOCKSS, CLOCKSS or PORTICO to ensure that content persists and can be made available in case of any complications arises from the publishers' end.

Communication to Users is also very significant in e-books execution strategies. In an academic environment, the knowledge manager or Librarian should create a widespread understanding and acceptance of eBooks within the library community before releasing such new initiatives of e-books implementation in the research libraries. The librarian should focus on the research output and should educate the users about the benefits of e-books collections, arranging awareness programs, should invite other librarians to share their stories who have made successful e-books transitions, availability of the subject content, business models etc. In addition, the librarian and the library e-resource purchase committee should invite all relevant personnel to discuss the library procedures and policies, budgetary sources for acquiring eBooks etc. System administrator of the institution and the Library technical Staff need to be involved for accomplishing technical formalities like loading MARC records etc. so that end users can find the texts they need. Evaluation of Usage through COUNTER Compliant usage statistics will create the argument of return on investment (ROI) and also helps the library to monitor the speed at which users are embracing e-book collections and the research methods they are adopting. The usage of online content is driven by visibility and discoverability of the content in major search engines such as Google etc.Publishers should provide tools, case studies, and client references to address the majority of institutional needs, and any new suggestions will drive business and product development in the future. In a nutshell, Librarian should promote the subscribed e-book collection to users to get the most out from e-Book investments.

Usage Matrics :e-Book usage is still in the early stages to gain mass acceptance in India.However, a couple of matrices on e-books usage can be demarcated(by one of the leading STM publishers Springer) to justify the implementation of e-books in academic and research library.

Table 1-e-Book usage metrics to investigate

\begin{tabular}{|l|l|l|}
\hline Metric & Description & $\begin{array}{l}\text { Comments } \\
\text { Title Reach }\end{array}$ \\
$\begin{array}{l}\text { Number of book titles } \\
\text { that have been used }\end{array}$ & $\begin{array}{l}\text { Useful metric. In Print } \\
\text { environment, many books } \\
\text { were never takenout from } \\
\text { the shelf, whereas Google } \\
\text { and MARC records } \\
\text { available in online } \\
\text { environment make "less } \\
\text { popular" books visible to } \\
\text { its (smaller) audience. }\end{array}$ \\
\hline Cost per use & $\begin{array}{l}\text { Price paid divided by } \\
\text { number of uses }\end{array}$ & $\begin{array}{l}\text { Somewhat useful. This is } \\
\text { generic and an average. } \\
\text { May be useful in proving } \\
\text { ROI if figures are high. } \\
\text { But incase of ownership } \\
\text { modele-books purchase, } \\
\text { this will decrease over the }\end{array}$ \\
\hline
\end{tabular}




\begin{tabular}{|l|l|l|}
\hline & & years. \\
\hline $\begin{array}{l}\text { Cost per title } \\
\text { used }\end{array}$ & $\begin{array}{l}\text { Total Cost divided by } \\
\text { number of titles with } \\
\text { usage }\end{array}$ & $\begin{array}{l}\text { Somewhat useful, } \\
\text { however because books } \\
\text { can be accessed } \\
\text { perpetually, the cost will } \\
\text { go down over the years. }\end{array}$ \\
\hline $\begin{array}{l}\text { Age of used } \\
\text { books }\end{array}$ & $\begin{array}{l}\text { Is the age of books } \\
\text { relevant when used? }\end{array}$ & $\begin{array}{l}\text { Slightly older books are } \\
\text { used nearly as frequently } \\
\text { as newer books. } \\
\text { e-book collection keeps its } \\
\text { value over the years. }\end{array}$ \\
\hline $\begin{array}{l}\text { eBook usage } \\
\text { compared to } \\
\text { journal usage }\end{array}$ & $\begin{array}{l}\text { eBook chapter usage } \\
\text { compared journal } \\
\text { article usage. }\end{array}$ & $\begin{array}{l}\text { "Journalization" of book } \\
\text { content makes "chapter" } \\
\text { and "articles" more } \\
\text { similar. }\end{array}$ \\
\hline \multicolumn{2}{|c|}{}
\end{tabular}

\section{Future prospects for eBooks}

With the advent of ICT and users growing necessity in the academic realm, it is very clear that there will be a far-reaching transition to electronic books. However, licensing agreements, access feasibility, identification of access mechanism are some of the technical issues or challenges that remain in e-books implementation and need to be checked thoroughly to avoid the delay in library user services. The printed book will never cease to exist. Libraries of the future may look different, with e-resources accounting for a larger contribution of total holdings. But still the traditional print resources will occupy library shelves, library patrons will access eBooks and other electronic resources via computer terminals or from remote locations.

More dedicated e-Book readers such as "electronic ink devices", as well as mobile phones and PDAs are becoming more popular every day and had overcome the problems perceived with computer screen reading. These devices have a paper-like static screen, and consume very few power. Users have the ability to bring hundreds of books on one device, that reads like paper. Though these e-readers has its own minor disadvantages in some cases, however, difficulties in reading from computer or PDA screen can be eradicated by replacing with better readable screen and an opportunity to bring many titles in one device. By giving students and researchers access to large e-Book collections, they are given access to a valuable database of content. Search engines and library catalogues play the most important role by making e-Books findable and used, and thus make them able to find exactly the content they need, from a critical mass which is indeed a great advantagefor research and study as well.

\section{CONCLUSION:}

The emergence of e-books as a central part of the information experience requires libraries to think differently about how to meet the needs of their users. Findability and ease of use are the most important features to convince the student\& researchers on the practice of using e-books which in turn led the usage drive and enhance the research output in an institution. While eBooks will not replace print books in the near future, users are rapidly adopting them as complementary to print books. Users value the e-books because of its convenience and ease of access and so researchers are getting engaged in new forms of book content usage to take advantage of their libraries collection. So, Libraries should expand e-Books usage to an even larger population of users by raising awareness of e-Book availability and ensuring that eBook content is easy to find and use. 


\section{REFERENCES :}

[1] Patil Y M (2014), Consortium Approach to Resource sharing in an E-Environment, Scientific Publishers,India, pp.42-43

[2] Arora J (2001), INDEST- a proposal for strategic cooperation for consortia based access to electronic resources Interenational Inf. and Library Review 33(2-3):149-165

[3] Arora J (2003) Indian Digital Library in Science and Technology (INDEST) Consortium, An Initiative by Ministry of MHRD, GOI,10p, http://www.library.iitb.ac.in/indest/

[4] Cleto Cynthia (2008), ATG Special Report - 10 Steps to Implementing an eBook Collection: A Guide for Librarians, Against The Grain ( Feb, 2008) <http://www.against-the-grain.com>

[5] Springer Whitepaper2007 eBooks - Costs and Benefits to Academic and Research Libraries, Springer, www.springer.com

[6] Springer Whitepaper2008,eBooks - The End User Perspective, 2008 Springer(www.springer.com)

[7] Springer White paper, 2007 "10 steps to Implementing an eBook Collection - A Guide for Librarians", 2007 - Springer (www.springer.com)

[8] Blummer B (2006) E-books revisited. Internet Reference Services Quarterly 11(2): 1-13.

[9] e-book ,2008, Are Librarians and Publishers on the Same Page, Publishers Communication Group (2008)

[10] JISC National E-Books Observatory Project, Results of First User Survey Joint Information Systems Committee (JISC), 2008

[11] Information Behaviour of the Researcher of the Future, Centre for Information Behaviour and the Evaluation of Research (CIBER), 2008

[12] Nicholas David, Huntington Paul, Rowlands Ian,Dobrowolski Tom and Jamali H (2007), What Do Faculty and Students Really Think About eBooks?,University College London, UK

[13] http://www.puballey.com 